\title{
ROLE OF HR TECHNOLOGY AND TRAINING FOR THE DEVELOPMENT OF EMPLOYEES
}

\author{
Narjis Batool \\ Bahauddin Zakariya University, Multan, Pakistan \\ E-mail: narjisbatool856@gmail.com \\ Sajid Hussain \\ Bahauddin Zakariya University, Multan, Pakistan \\ E-mail: sajid.hussain6441@gmail.com \\ Muhammad Baqir \\ University of Education Lahore, Multan Campus, Pakistan \\ E-mail: baqiralisiddique@gmail.com \\ K. M. Anwarul Islam \\ Associate Professor \\ Department of Business Administration \\ The Millennium University, Dhaka, Bangladesh \\ E-mail: ai419bankingdu@gmail.com \\ Muhammad Hanif \\ Bahauddin Zakariya University, Multan, Pakistan \\ E-mail: malikhanif1556786@gmail.com
}

\begin{abstract}
The purpose of this article is to explore the factors and importance of training for developing the employees and focus that how HR technology and e. practices help the HR consultants to make the training more efficient, and what type of technology used in training, and how to improve the training that helps in employees development. The data collection is done by online questionnaire. For this study, 305 respondents fill the questionnaire, and for data, use the primary data. For the imperial foundation of this article, we use the PLS software for analysis. The analysis found that the training plays an essential role in developing the employees. There are positive responses of people about the role of technology and training in organizations. Many employees agree that they need training in the organization to benefit both employees and the company. For this study, we collect the data from different responses and use the convenient approach. This study's challenge is what types of technology improve the quality of training and how employees understand it easily. Training the employees becomes more proactive and how they influence the activity.
\end{abstract}

Keywords: Employee Developments, Training, Emotional Intelligence, HR Practices.

JEL Classification Codes: O15, N7, P36, J54. 


\section{INTRODUCTION}

Today, people shifted from the traditional to the advanced era because of competition in business, and everyone wants to compete (Podgorodnichenko, Edgar, \& McAndrew, 2020). For this purpose, organizations need to develop their employees because people are the key element (Adli, Gharib, Hakami, \& Pourmahdi, 2014). If employees are not developing themselves, their performance will reduce. A day HRM focuses on developing their employees with the help of different methods like training and E. HR practices (Gope, Elia, \& Passiante, 2018). Organizations need skilled people in every field because they are the assets of any company (Parry \& Battista, 2019). There is a positive relationship between training and HR technology and their impact on employees' performance. Training plays an important role in the development of employees (Tahir, Yousafzai, Jan, \& Hashim, 2014). It enhances the employee's skills, behavior, knowledge, personality, and performance. HR technology plays an important role in enhancing the employees' performance (Cooke, Schuler, \& Varma, 2020).

The organizations conduct different training and that different technique are applied to engage the employees for better performance (Tahir et al., 2014). Technological advancement in the organization enhanced the skills, and it helps the employees and makes their work more flexible (Florkowski, 2018). There are different types of training like management training, software training, employee motivational training, etc. A day HR of any organization enhances and promotes new technology and training to engage the people towards more productivity (Tahir et al., 2014). If employees are happy and internally satisfied, their performance automatically increased. Companies face many challenges about training and managing the employees because it is difficult to understand every employee's motive and how to attract them towards more productivity. HR plays a key role in attracting, retain, and manage employees by conducting different practices (Adli et al., 2014).

There is a relationship between training and HR technology. They help the employees develop their skills, knowledge, learning abilities and promote emotional intelligence (Cooke et al., 2020). This paper explores the impact or role of HR technology and training on employees' development and how people manage themselves in any situation because most people do not manage and understand their emotions. As a result, they could not be satisfied with one job, and most employee's turnover from that job because they are not satisfied with their job (Stahl, Brewster, Collings, \& Hajro, 2020).

\section{BACKGROUND OF THE STUDY}

In the previous study, the author explores the impact of training on employee performance. Still, this article is based on the factors that affect employees and how training and technology develop employees, and how they increase employees' performance (Adli et al., 2014). This study focuses on qualitative research based on different research papers and case studies. The article explores that how training and technology impact the five essential functions of HRM (recruitment, selection, hiring, promotions, and development of employees). Many organizations face competition globally, so they need more advancement in every field (Florkowski, 2018). Human resources are a significant part of any organization's assets because, through employees' performance, they get a competitive advantage (Gope et al., 2018). 


\section{LITERATURE REVIEW}

HRM helps the organization develop and sustain employees; HR managers make the policy for manage the employees. They engage the people by different methods for better performance in the organization (Gope et al., 2018). Some companies hire the consultant to apply the strategies and practices to achieve the organization's result and sustainable growth. Many organizations face failure in engaging and developing their employees because they should not properly conduct the training due to the employee's loss of interest in the job and that employees' performance reduces. HR technology and training play an essential role in the development of employees.

In the previous study, the authors are discussed the HRM policies and strategies and how HR develops the employees through training (Florkowski, 2018). We have to identify the research gap in how HR technology and training play a role in developing the employees and the relations between training and HR technology that relates to each other's and through which types of training need employees for development. In Pakistan, different companies adopted the IT system to develop their employees towards greater performance (Stahl et al., 2020). Some multinational companies have their institute where employees and even their top management facilitate with training. For succession planning, training plays an important role in developing the applicable people for top positions (Cooke et al., 2020). For top management, technology training influences employees' positive impact for improving communication skills, better decision-making skills enhanced manage their own emotions and how to run their companies people (Stahl et al., 2020). Technology makes HR more advanced, and due to that, it less timeconsuming and helps the HR expertise to more understanding the purpose of training (Hanif \& Qurashi, 2020). The employees can easily understate training by different methods like live sessions, PowerPoint presentations, simulations, videos, and tutorials (Nassazi, 2013). Many researchers believed that an HR practice helps the employees to achieve success by creating and sharing ideas (Tahir et al., 2014).

Sustainable human resource management adopted the strategies and practices that help achieve organization goals (Florkowski, 2018). Some training positively and some result in negative impacts that affect the overall organization (Cooke et al., 2020). For positive outcomes, HRM needs multidimensional practices. Training and new technology make it easier, but some companies face problems about usage and technology adoption. This article focuses on the HR practices to developing the employees and how HR technology influences' and technology helps train the employees (Stahl et al., 2020). In that advanced era, technology helps in every field, so it plays an important role in employees' training. Through advanced HR practices enhanced the employee's performance. In this article, we disallowed the variables which impact employee's performance.

\section{Impact of HR Technology on Training}

Technology plays an essential role in training, and now different companies adopt the technology for more advancements and benefits, but many employees not used that technology appropriately. Hence, companies gave them the training to achieve their goals properly (Nassazi, 2013). Technology makes the training easier, and employees understand it easily. Different technology like simulations, tutorials, motivational videos, and others HR practices help the employees to understand the purpose of training (Tahir et al., 2014). HR practices are the independent variables that impact training and play a key role in employee development. The trainer or consultant's role is to identify the need for training, and he shifts the traditional and straightforward way into new and active and advancement in the trainee. If the employees are 
well trained, they adopt the latest technology quickly and show their interest in their jobs. Due to less absenteeism and employee turnover rate, it will be reduced (Gope et al., 2018). A good or skillful trainer can save time and money for both company and employees by conducting perfect training in which there is the advancement and follow the new technology and practices in the training.

\section{How Training Develop the Employees}

Training is an essential function of HRM; if the companies did not deliver the training properly, its effect negatively on the overall organization (Parry \& Battista, 2019). Training has a positive effect on employee's development. Through the training, employees feel satisfied. Their performance should increase by talent management training, manage culture diversity, and manage their own emotions. Training motivates the employees towards positive work performance. Most organizations deal globally, so training plays an essential role in working and managing outside the organization (Cooke et al., 2020). This research training plays a mediator role that impacts both $\mathrm{hr}$ technology and employees' development. There are different training types like OJT (on-the-job training), mentoring and coaching, computer-based training, simulation, and motivation training; through the different practices, we trained the employees during the job and before starting the job.

\section{Role of Emotional Intelligence on Employees' Performance}

Emotions are a factor through which an employee's behavior should b positive or negative. If an employee tends to control their own emotions at work, their performance should be increased. Most employees should not be aware of emotional intelligence, so they should not easily manage themselves and their work (Cooke et al., 2020). Now HR managers focused on emotion intelligence training mostly organizations conduct different training to controls and understand their own interest emotions and how to manage others (Nassazi, 2013). Emotional intelligence tells the employees how to behave positively during work. Emotional intelligence has a positive impact on the employee's performance. Through the training, employee increases the selfassessment and self-development and for that emotional intelligence plays an important role in developing the personal skills of any employees.

\section{Development of Employees through HR Practices}

Employee development is the dependent variable. It depends on training and HR practices (Tahir et al., 2014). Employees are the main source of profits in any organization. If they are not satisfied with their job, then the turnover rate will $b$ increased, so there are necessary to develop the employees. Many companies provide facilities for employees if the employees face a lack in their performance. The companies conduct training and different interesting and motivational practices through which they easily understand. These practices should help to increase the performance of employees. Employee's performance depends upon training and advance practices. If the way of delivering is positive, then their impact on developing the employees should $b$ positive.

\section{CONCEPTUAL FRAMEWORK}

For this research, we have chosen the four variables, and they relate to each other's, and they are positively associated with each other's i.e. 


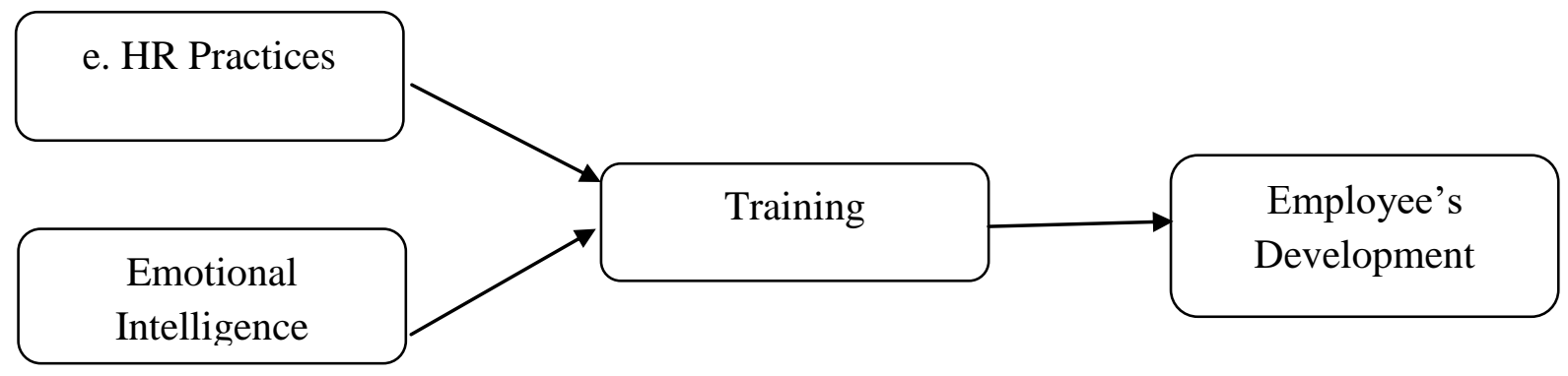

Figure1. The theoretical framework of HR Technology and Training for the development of Employees

The framework consists of two independent variables and one mediator variable which affect employees' development - the e.HR practices (HR technology influences practices) have a positive impact on the training of employees. If the training is delivered in effective ways and technology helps the employees understand the purpose of training (Tahir et al., 2014). Technology-enhanced training and its impact are positive on both training and employee development (Florkowski, 2018). Technology and training are learned and planned programs that help the employees manage current or future work (Stahl et al., 2020). They prepare the employees for future development and contribute to their compelling performances (Kock, Wallo, Nilsson, \& Höglund, 2012). It is a continuous process to develop the employees when they face any lack or problems at any stage. Emotional intelligence is independent variables that also affect the employee's development if the employees control their emotions and understand others' interest and culture. Through emotional intelligence, the employees avoid conflicts, and they feel happy and satisfied because their performance increased.

Technology and digital information and communication change the various activities of the organization. Technology and E. practices have a positive impact on employee satisfaction. HRM managers now focused on the factors that satisfied the employees and conducted different training like motivational programs, culture management training, goals achievement training, how to manage innovation, and adopt the change in the organizations (Cooke et al., 2020). In the previous research, the searchers debate the misalignment between technology (IT) and training (Tahir et al., 2014). This debate arises to understanding that what type of technology and practices help the employees to develop them. So, according to the theoretical framework, it is clear that the training and others HR practices positively impact the development of employees, and all the variables are positively interlinked to each other (Stahl et al., 2020).

\section{PROBLEM STATEMENT}

This research is conduct to explore the relationship between training and technology on employee's development and their performance and the impact of training on employees, and what types of technology help train the employees in today's era. This article has explored answering how and why the training develops the employees. From the HR point of view, it focuses on motivating the employees through training because it's a learning activity and has an impact on employees' behavior (Nassazi, 2013). This study is useful for managers and executives, and it tries to fill the gap and build a strong relationship between HR technology and training for developing the employees (Adli et al., 2014). Some companies face problems during conducting practices so overcome these issues, we explore what type of strategies they need to 
motivate the employees and through what resources and practices employees easily understand the motive of training, how to resolve the conflicts among employees, stress reliving and it helps to move towards future goals and how to achieve it (Kock et al., 2012).

\section{METHODOLOGY}

There are different approaches and methods to analyze and synthesize literature data collections from other people. For this study, we collected the data from the various sources and followed the primary data like different scales from the previous research, websites case studies, and other research blogs (Kock et al., 2012). There are various categories for the collection of data. This study is based on qualitative data because we can quickly identify how and through what purpose we collected the data through the methodology. For that purpose, we collected the data from different methods in methods.

\section{Population and Sample Size}

For this research, we collected the data from an online questionnaire. And our population are mostly employees and some are students who are already working in any organization. We collected the data from 305 people who mainly belong to 30-50 years old employees working in private and government companies (Tahir et al., 2014). Our population belongs to males and females. According to responses, $34 \%$ are women, and $65 \%$ are males who filled the online questionnaire. And $13 \%$ are students, and $86 \%$ are the employees who fill the questionnaire through online.

\section{Sampling Techniques}

For collecting the data, researchers use different sampling techniques according to their study. For this study, we adopt the convenience sampling technique because it is very easy and useful for collecting the data. We collect data from those people (respondents) who are easily available to fill the questionnaire through this technique. This technique is not compulsory to fill the questionnaire from a specific group of people. So we adopt this technique for collecting the data.

\section{Data Collection Tool}

For this study, the Likert scale is used as a data collection tool; we have used five-point scales from strongly agree to disagree strongly. This Likert tool is the best and standard tool used in data collection; most researchers used this frequently because we measure and collect data easily from our respondents through the Likert scale. Through this collection tool, the respondents can easily understand and feel relax to fill the questionnaire.

\section{DATA ANALYSIS}

There are different software for analyzing the data for this study we conduct analysis through the smart PLS3; we analyze this software because the result and analysis are accurate and it is easy to use, and through the PLS, we can do the analysis for dual times through this we can get more accuracy in our result (Kock et al., 2012). For data analysis in PLS, at least 300 responses are needed. We have completed 305 responses for data analysis and choose this software because it gathered all the models, and through PLS structure equation model is done easily. 
Table 1. Reliability and Validity

\begin{tabular}{|l|l|l|l|l|l|}
\hline Construct & Items & Loadings & Cronbach's Alpha & CR & AVE \\
\hline & ED1 & 0.014 & 0.229 & 0.34 & 0.325 \\
\hline Employees & ED2 & 0.789 & & & \\
\hline Development & ED3 & 0.659 & & & \\
\hline & ED4 & 0.002 & & & \\
\hline & EI1 & 0.644 & & & \\
\hline Emotional & EI2 & 0.595 & 0.08 & 0.026 & 0.345 \\
\hline Intelligence & EI3 & 0.518 & & & \\
\hline & ET1 & 0.742 & & & \\
\hline & ET2 & -0.123 & & & \\
\hline Employees & ET3 & 0.679 & 0.076 & 0.077 & 0.264 \\
\hline Training & ET4 & 0.043 & & & \\
\hline & ET5 & 0.51 & & 0.135 & 0.258 \\
\hline $\begin{array}{l}\text { Human } \\
\text { Resources }\end{array}$ & HRD 1 & 0.345 & 0.144 & & \\
\hline Development & HRD2 & 0.38 & & & \\
\hline & HRD3 & 0.816 & & & \\
\hline & HRD4 & 0.61 & & & \\
\hline
\end{tabular}

Source: Kock et al., 2012

This table constructed the reliability and validity of variables, and every question has its factor loadings. Every variable has the value of Cronbach alpha. According to our analysis, Alpha's value is more significant than 0.7 , so its means it is acceptable. All variable has more then 0.7 values means this analysis is valid and acceptable. There are the values of factor loading means it shows the variables in the structural equation model. The average variances value lies between 0.4-0.3. So the average variance is acceptable according to our analysis. So, according to the above criteria and values, it is clear that all variables' reliability and validity are accurate. Because the value of alpha of all variables is $<0.7$ so our result is accurate and perfect.

Table 2. Discriminant validity

\begin{tabular}{|l|l|l|l|}
\hline HRD & EI & ED & ET \\
\hline 0.57 & & & \\
\hline 0.392 & 0.588 & & \\
\hline 0.204 & 0.266 & 0.514 & \\
\hline 0.332 & 0.229 & 0.179 & 0.508 \\
\hline
\end{tabular}

Source: Kock et al., 2012

The discriminant validity shows the relationship of variables with their indicators means they have a strong assessment or not it shows the correlation between the variables, so during the analysis in PLS software, it ensures that there are strong relations and indicators between the variables. In our study, there are four variables, and one is a mediator. Discriminant validity mostly lies between two scales and the acceptable values to check the validity of variables it 
should be less the $>0.85$; according to our analysis, all the variables are less than 0.85 , so it is clear that all the variables are strong relationship and show the positive indicators with others variables, so the result of validity of all variables shows the strong relationship and all the values show the positive result.

Table 3. Heterorait-Monotrait (HTMT)

\begin{tabular}{|l|l|l|l|l|}
\hline & HRD & EI & ED & ET \\
\hline HRD & & & & \\
\hline EI & 0.85 & & & \\
\hline ED & 0.976 & 0.874 & & \\
\hline ET & 0.571 & 0.317 & 0.633 & \\
\hline
\end{tabular}

Source: Kock et al., 2012

This table shows the relations between the variables and ratio of correlation means which variable are correlated to each other, to check the correlation the HTMT value should be $>0.90$ and according to our analysis all the variables has less the values from 0.90 so from that it is clear that all the variables are correlated to each other like the employee's development depend on the training and e. HRD practices, because they have a strong relationship with each other, show a positive attitude than others will be increased because they are directly related to teaching others (Florkowski, 2018). The HTMT values are the comparing of threshold if the values of those variables are increasing from the threshold, it means there are lacks in the discriminant validity and that variables are not valid for the analysis.

\section{Structural Model Assessment}

After the measurement models, we are now conducting the structural assessment model through the smart PLS3. This model is performed by bootstrapping and analysis of 305 responses to describing the structural equation model. Some variables are interlinked to each other.

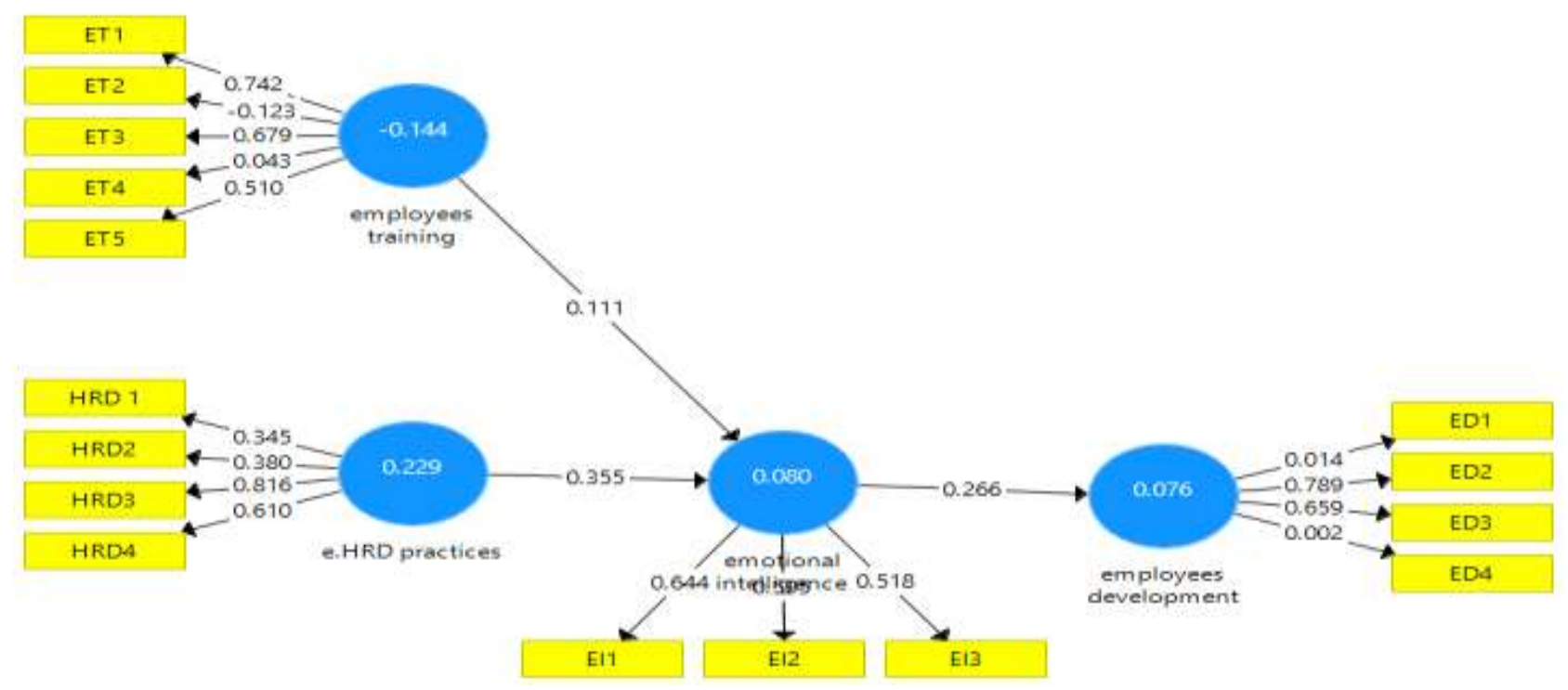

Figure 2. Structural Model Assessment

Source: Kock et al., 2012 
Different variables are linked to each other in that model, like two variables are independent and their value of Cronbach Alpha is given. Each question has its mean value, and according to that value, they are correlated to each other like training and e.HRD is connected to the mediators variable, and then these all affect the dependent variables.

Table 4. Structural Model Results

\begin{tabular}{|l|l|l|l|l|}
\hline Variables & Beta & Std. Error & T value & P Values \\
\hline e.HRD & 0.355 & 0.369 & 4.339 & 0 \\
\hline EI & 0.266 & 0.299 & 3.546 & 0 \\
\hline ED & 0.111 & 0.145 & 1.501 & 0.134 \\
\hline
\end{tabular}

Source: Kock et al., 2012

This result shows the positive relationship between the variables the human resources development has the beta value (0.335 and t value is 4.339$)$ it means that this value has a positive and strong relationship with the others variables and according to that the moderator emotional intelligence has the values of beta (0.266) and the $p$ values is 0.134 and according to that values its effects on both variables on dependent and independent variables if one has positive attitude then other has also positive relation.

Table 5. Fit Model: Goodness of Data

\begin{tabular}{|l|l|l|}
\hline & Saturated Model & Estimated Model \\
\hline SRMR & 0.125 & 0.125 \\
\hline d_ULS & 2.134 & 2.14 \\
\hline d_G & 0.418 & 0.421 \\
\hline Chi-Square & 687.419 & 687.964 \\
\hline NFI & -0.201 & -0.202 \\
\hline
\end{tabular}

Source: Kock et al., 2012

The fit model indicates the correlation and covariance matrices between the variables during the structural equation model (SEM), this model helps during the analysis to check that SEM is fit or not, and their result shows that the SEM model is fit for analysis this model is mostly used for the causal studies. The fit model indicates that the confirmatory and SEM models are acceptable or not acceptable. If the chi-square value is acceptable if the value of $\mathrm{p}$ in the results is $<0.05$, the chi-square shows the goodness of data in the fit model.

Table 6. Moderation Effect Results

\begin{tabular}{|l|l|l|l|l|}
\hline Variables & SSO & SSE & $\mathbf{Q}^{2}(=1-S S E / S S O)$ & Decision \\
\hline e.HRD & 1220 & 1220 & & Supported \\
\hline EI & 915 & 886.401 & 0.031 & Supported \\
\hline ED & 1220 & 1212.461 & 0.006 & Supported \\
\hline ET & 1525 & 1525 & & Supported \\
\hline
\end{tabular}

Source: Kock et al., 2012 
According to the moderation effect, it is clear our analysis supports the relationships and reliability. So from the above analysis, the result is positive and supported our study means that on which we are doing research are good, and all are variables are supported to each other's, and there is no negative effect for that study. According to the table, the $\mathrm{Q}$ value of emotional intelligence and its mediators variable has 0.006 , and 0.031 and this value shows that they directly relate to each other if there are better training of employees and people can manage and understand their emotions, employees easily develop. Their performance should also increase within the organization.

\section{Positive Effects of Training and Development}

The main purpose of training and learning is to provide the skills, acquire knowledge for doing the job, and gain promotion and future development. It develops the personal and professional careers of employees. There are different types of practices conducted by HR according to the need and situation to build the capacity skills of employees (Kock et al., 2012). Active training allows the trainee to perform works actively if trained by a good trainer or professional. Most companies adopt the new and advanced training method to become more effective and valuable for employees (Nassazi, 2013). Training is not beneficial only for companies. It increases the positive attitude and self-control on their emotions, and through the training, employees enhance their skills (Nassazi, 2013). It helps to build the morale of the workforce towards the productivity of the organization. If the training is not conducted correctly, it should be useless for both employees and companies and time-consuming and loss of money for training (Nassazi, 2013). There are different training conducts for employees for self-confidence, managing cultural diversity, practical problem solving, and increasing their productivity level. Training is the continuous process of learning, knowledge for more work effectively. Development of employees mostly refers to future goals and direction through training. HRM has the main function to develop their employees through training because managing the people is a more tough job because people have different norms and values and interests in the organization, so understand their problems and address them is the responsibility of a good HR professional. HRD belongs to the training and development process. HR consultant ( trainer) is the main function to identify the need for training. It means what type of training employees need and what purpose they conduct training. The most element is that employees benefit from the training they easily understand. Trainers need to take feedback from the employees after completing training.

\section{Role of Technology in Training}

Technology has become the key element for any organization's success and helps in every field of life or organization (Hanif \& Qurashi, 2020). Nowadays, people have become more advanced and want a more comfortable environment at the workplace. In training now, technology plays an important role. By adopting the different methods and advancement in training, employees are satisfied and easily understand the training purpose. It creates value for the trainee; due to the new technology, people can easily collaborate and easily understand their motive (Cooke et al., 2020). Now HR consultant is focusing to adopting the latest methods for training like online collaboration through this people can easily interlink to each other at any place at any time, this technology is more beneficial for multinational companies, a trainer conduct meeting and different people from different countries can collaborate (Nassazi, 2013). There are different management components like HRT (Human Resource Technology) that play an important role $n$ a company to motive the employees and helping them for easier their work. Virtual HR enhance 
the new capabilities in the employees, and it is less time consuming; if this technology is not used properly, then it affects both employees and its companies because when we implement the change or new technology in the organization, it's very expensive, so it's necessary to see the positive aspects of technology. There are two types of training. Technical training mostly focuses on improving the employee's technical skills, software knowledge, and technology. Still, the development training focuses on the employee's skills like self-confidence, motivation, and culture management conflict management (Nassazi, 2013). Technologist advancement became the training more efficient and increased employees' competencies and capabilities (Stahl et al., 2020).

\section{FUTURE RECOMMENDATIONS}

This article focuses on using the technology in the training of employees and these HR practices that belong to different e. practices this latest technology used during the training helps develop the employees. The technology makes the training more effective, which has a good impact on the employee's performance. In the traditional training method, employees face difficulty understanding the motive and purpose of training (Tahir et al., 2014). In this article, we have tried to fill all the gaps we observed from the previous research. But there are some recommendations for future research, which are the following.

- HR professionals or practitioners need to prepare themselves for future planning to motivate the employees through new and easy methods; they should follow the different kinds of technology, making the training more effective and understandable for employees.

- For further study, the researcher needs to make that type of strategy and practices through which employees can attend training from anywhere they should communicate and participate easily, so its responsibility of HRM that how to manage and adopt new and easy techniques for training the employees that result should be more accurate.

- To understand the relationship between HR and technology with the training, they need to survey the different HR professionals. These industry experts conduct the training for employees and play an essential role in its contribution.

- There is a need to research training and development in Pakistan's region where there is a lack of exercise and technology like banks of Peshawar because, in banks, they focus more on organizations' productivity and efficiency.

\section{CONCLUSION}

This study has provided an overview about the importance of training and e. HR practices and how it helps in developing the employees (Kock et al., 2012). For sustainable organization how HRM strategies and training play a key role to develop the organization, HR managers need to adopt professional activities to develop their employees. There are some components on which employees should need training like leadership, culture management, stress-relieving, and good performance. Some companies face conflicts that are different types like conflicts of interest, conflicts between employees, and the lack of the best workplace. To overcome these issues, HRM practitioner's and managers' responsibility is to identify the better solution for developing their employees. This article has multiple theoretical lenses to explore and understand the impact of training and practices, which helps both company and employees' performances. It is a continuous learning activity for employees; a good HR manager identifies the gap and training 
needs. This means in which area the employees face lack and need training; then HRM makes the policies and strategies to train employees.

Technology made people more reluctant, and they feel comfortable due to adopting the technology. Still, some companies face the issues because their employees could not understand the new technology and change within the organization. Hence, it's the company's responsibility to motivate the employees to adopt that change. HRM practices help the employees to work in a comfortable zone. All the companies, either government or non-government, conduct training, to develop employees; some multinational companies conduct the different practices for employees' future planning and how they are emotionally attached to their work. Different type of technology helps the HR manager in trainings because technology made the employee training more understandable for employees. For multinational company's electronics practices become faster like conference calls, online video tutorial, links or other websites are helps in training the employees. Companies are now going to international level and to manage the culture and people interest HRM plays an important role in developing and grooming the employees for current and future planning.

Technology has a prominent effect on the HRM because it improved the accuracy of employees training and due to best training the result will also fruitful. Training need analysis is the main component of a successful HR if they could not conduct the right training for the right person it should harm the organization and employees' performance.

\section{REFERENCES}

Adli, M., Gharib, S., Hakami, M., \& Pourmahdi, K. (2014). A Survey on Electronic Human Resource Management Consequences, Its Outcomes and Performances. Journal of Basic and Applied, 4(10), 71-82.

Cooke, F. L., Schuler, R., \& Varma, A. (2020). Human resource management research and practice in Asia: Past, present and future. Human Resource Management Review, 30(4), 100778.

Florkowski, G. W. (2018). HR Technology Systems: An Evidence-Based Approach to Construct Measurement. In Research in Personnel and Human Resources Management. Emerald Publishing Limited.

Gope, S., Elia, G., \& Passiante, G. (2018). The effect of HRM practices on knowledge management capacity: a comparative study in Indian IT industry. Journal of Knowledge Management.

Hanif, M. I., \& Qureshi, Z. S. (2020). Effect of Employer Branding Attributes on Talent Retention with mediating Role of Transformational Leadership. Sustainable Business and Society in Emerging Economies, 2(1), 47-54.

Kock, H., Wallo, A., Nilsson, B., \& Höglund, C. (2012). Outsourcing HR services: the role of human resource intermediaries. European Journal of Training and Development, 36(8), 772-790. 
Nassazi, A. (2013). Effect of Training on Employees performance: Evidence from uganda. (Doctoral dissertation, Theseus). Retrieved from https://core.ac.uk/download/pdf/38098025.pdf

Parry, E., \& Battista, V. (2019). The impact of emerging technologies on work: a review of the evidence and implications for the human resource function. Emerald Open Research, $1(5), 5$.

Podgorodnichenko, N., Edgar, F., \& McAndrew, I. (2020). The role of HRM in developing sustainable organizations: Contemporary challenges and contradictions. Human Resource Management Review, 30(3), 100685.

Stahl, G. K., Brewster, C. J., Collings, D. G., \& Hajro, A. (2020). Enhancing the role of human resource management in corporate sustainability and social responsibility: A multistakeholder, multidimensional approach to HRM. Human Resource Management Review, 30(3), 100708.

Tahir, N., Yousafzai, I. K., Jan, S., \& Hashim, M. (2014). The impact of training and development on employees performance and productivity a case study of United Bank Limited Peshawar City, KPK, Pakistan. International Journal of Academic Research in Business and Social Sciences, 4(4), 86.

\section{Copyrights}

Copyright for this article is retained by the author(s), with first publication rights granted to the journal. This is an open-access article distributed under the terms and conditions of the Creative Commons Attribution license (http://creativecommons.org/licenses/by/4.0/) 